\title{
Exploration on Characteristics of Idea Discovery Process Based on Assumption Reversal Thinking Skill: Focusing on Undergraduate Students in Korea
}

\author{
Jihyun Yoon ${ }^{1}$, Ji-Young Park ${ }^{2}$, Seong-Joo Kang ${ }^{2, *}$ \\ ${ }^{1}$ Department of Pedagogy, Dankook University, Jukjeon, Korea \\ ${ }^{2}$ Department of Chemistry Education, Korea National University of Education, Chung-Buk, Korea \\ *Corresponding author: sjkang@knue.ac.kr
}

Received September 27, 2014; Revised October 27, 2014; Accepted October 30, 2014

\begin{abstract}
The core of the creative problem solving is the idea discovery process. However, Korean students are shown the idea discovery process more difficult than other processes in the creative problem solving. Thus, there is a need to provide in detail the methodological aspect to induce ideas for Korean students. This research examined the elements and the characteristics appearing in the idea discovery process based on assumption reversal thinking skill by Korea's undergraduate students. As a result of the research, the idea discovery process applying the assumption reversal thinking skill could be classified into the idea generation phase and the idea evaluation phase. In addition, in the idea generation phase, 'search for assumption reversal object', 'extraction of internal or external attributes of assumption reversal object', and 'idea generation through assumption reversal thinking skill' elements could be confirmed. In the idea evaluation phase, 'evaluation standard setting', 'evaluation', and 'prototype' elements could be confirmed. The circulation of elements appearing in the idea discovery process could be confirmed as well. For example, the idea generation phase and the idea evaluation phase were repetitively circulated by closely interacting with each other. In the idea evaluation phase, the evaluation-related elements were repetitively circulated by closely interacting with each other, and in this case, two circulation types could be observed. For example, in some groups, the 'evaluation standard setting', 'suitability evaluation of idea through prototype', 'idea disposal and generation', or 'final idea selection' were circulated. In other groups, the circulation was conducted in two stages, and in the first stage, the 'evaluation standard setting', 'idea evaluation pursuant to the evaluation standard', 'idea disposal', and 'idea generation' were circulated. In the second stage, the 'prototype of idea passing the evaluation standard', 'idea evaluation through prototype', 'idea disposal and generation', or 'final idea selection' were circulated. The educational implications were discussed.
\end{abstract}

Keywords: assumption reversal thinking skill, idea discovery process, Korean undergraduate student

Cite This Article: Jihyun Yoon, Ji-Young Park, and Seong-Joo Kang, "Exploration on Characteristics of Idea Discovery Process Based on Assumption Reversal Thinking Skill: Focusing on Undergraduate Students in Korea.” American Journal of Educational Research, vol. 2, no. 10 (2014): 981-989. doi: 10.12691/education-2$10-20$.

\section{Introduction}

Creativity is being emphasized as one of the core capabilities to live a successful life in the knowledgebased society of the 21st century. Thus, creativity enhancement of students through school education has been considered as one of the important educational policies in most of the nations around the world. Creativity education of students has been emphasized in Korea as well, and in particular, as the Korean society converted into a first moving economy model by escaping from a fast following economy model. It is further emphasizing the cultivation of creativity, which is one of the core values necessary for the first moving economy. Thus, Korea has researched and developed creativitycentered education programs by establishing the basic direction of educational reform as cultivation of creative Koreans, and has organized and is operating such programs at the school education field. In addition, efforts are being made to develop teaching learning programs that may be utilized in curriculum activities per grade and level, and to apply or spread such development in the school education field.

Science education in Korea is emphasizing the enhancement of creative problem solving capability in order to enhance the creativity of students $[1,2]$. Creative problem solving means efforts by an individual or a group to think creatively in order to solve a certain problem, since functions of creative thinking, such as divergent or convergent thinking, can be cultivated in the process of discovering a problem and finding a solution for the problem [3]. Accordingly, the objective of science education in Korea is moving towards enhancing creative problem solving capability from understanding scientific 
knowledge, and the increase of creative problem solving capability of students was proposed as the educational objective for the first time in the revised science curriculum in 2007. Thus, programs having the objective to cultivate creative thinking in the process of solving problems by utilizing science knowledge are being provided to students in the science education field in Korea.

Most of the creative problem solving programs utilized at Korea's science education field are composed of the three processes, which are problem discovery, idea discovery, and idea implementation processes. And each process includes detailed strategies or skills to assist activities of students per process, considering the teaching and learning situation of Korea and the level or characteristics of students [4,5,6]. For example, the brainstorming skill, which is a method of generating ideas through habitual and transitory thinking without formalities of a certain type of thinking, is mostly used in the idea discovery process [7].

However, studies show that Korean students have more difficulties and burden in the idea discovery process utilizing the brainstorming skill compared to other processes [8]. Brainstorming emphasizes free association of thinking in the early process of idea discovery [7], however, in order to effectively achieve generation of ideas through free association, students must think outside the box and actively utilize their own experience or knowledge in forming ideas. However, most Korean students have generally received the knowledge-centered education for a long time while engaging in excessive competition to enter upper level schools. Despite the fact that creativity education is also emphasized by the government's active lead, the students may have found idea generation through free association as difficult, through lack of experience on effective utilization of experience or knowledge for idea generation. Thus, it may be more effective to provide an actualized idea generation method rather than emphasizing free association of ideas in the idea discovery process for Korean students. Accordingly, there is a need to consider assumption reversal [9], a frame of thinking for idea generation emphasized in sectors such as the economic and business administration.

Assumption reversal is a skill of thinking reversely of existing thoughts or characteristics regarding a problem, which means a new perspective of interpreting the current problem from other aspect $[9,10]$. Thus, because the assumption reversal thinking skill is a method of producing an idea by simply reversing or eliminating the internal or external attributes included in the object of problem, even students with almost no experience of idea generation may easily produce ideas for problem solving. In addition, because meaningful ideas for problem solving come out from a high number of ideas, the quantity of ideas rather than the quality is more important in the initial process of idea discovery [11]. And there is a possibility that ideas may be produced per number of attributes included in the problem object through the assumption reversal thinking skill. In particular, when considering the aspect that idea discovery starts from escaping fixed ideas [12], assumption reversal thinking skill, which is a method of producing ideas by reversing existing common sense, components, or preconditions, is expected to be usefully used to lead students to break out from fixed ideas.

However, researches relating to assumption reversal thinking skill have not been conducted in and abroad Korea, and in addition, there are an inadequate amount of relevant materials as well. Thus, there is a need to first conduct exploratory research to introduce the assumption reversal thinking skill into Korean science education and to obtain basic information in order to understand matters, such as the possibility of utilizing as an ideal cognitive skill. However, as there are no cases applying the assumption reversal thinking skill to elementary and secondary school students in Korea, this research first applied the assumption reversal thinking skill to undergraduate students in Korea, who can logically and specifically express their own thinking processes or activity contents compared to elementary and secondary school students.

Accordingly, this research explored the possibility of the assumption reversal thinking skill by examining the characteristics of the idea discovery process, by applying the assumption reversal thinking skill to undergraduate students in Korea.

\section{Methodology}

This research seeks to introduce the assumption reversal thinking skill in Korean science education and to obtain basic information in order to understand the possibility of the assumption reversal thinking skill as an idea generation strategy. In order to do such, this research conducted an exploratory study, which is regarded as an effective research method to discover new ideas or facts [13], and the details are as follows.

\subsection{Research Participants}

This research was conducted over 23 students studying at $\mathrm{H}$ University located in Chung-cheong-buk-do, Korea. The students were freshmen taking the general chemical experiment course, all majoring in chemistry education except one student majoring in elementary education. The general chemical experiment is a subject seeking to enhance understanding on general chemistry through experiments conducted by selecting basic and major themes among the contents dealt in general chemistry. There were no students that had participated in programs for gifted students in science or related activities. The students experienced the assumption reversal thinking skill for the first time through this program.

\subsection{Research Procedure and Application Method of the Assumption Reversal Thinking Skill}

This research was conducted in the general chemical experiment course, which was conducted once a week for two hours. Students participated in the activities adopting the assumption reversal thinking skill in the general chemical experiment course for three weeks.

First of all, a problem situation to apply the assumption reversal thinking skill was established. To do this, various themes of general chemical experiments were reviewed. And experiment theme that can be effective for generating 
new ideas by eliminating or transforming internal or external attributes of the given object was selected. Thus, a chemical cell experiment was selected through discussions between the researchers, and 'the idea discovery to produce a new chemical cell' was proposed as the problem situation to be solved by the students.

Subsequently, an orientation was provided on the assumption reversal thinking skill so that the students may become familiar with the skill. First, the importance of idea discovery process during the creative problem solving was explained, and the method of assumption reversal as a thinking skill, that may systematically assist discovery of diverse and unique ideas, was explained. It was suggested that the assumption reversal thinking skill is to think as ' $\mathrm{A}$ is not/does not have B' or 'Even though it is $A$, it can also become $C$ or $D$,' instead of stereotype thinking of ' $A$ is B.' It was also mentioned that $C$ could be B' (reverse of B) or can become a considerably different proposition from B even if not being B' $[9,10]$. After finishing the explanation, the students were allowed to practice the assumption reversal thinking skill over an electric fan. The students practiced assumption reversal of 'An electric fan has wings,' which is one of the characteristics of an electric fan, into thinking as 'An electric fan does not have wings' ('A is not/does not have $B$ ' type), and reversal of 'An electric fan operates through electric energy' into thinking as 'An electric fan operates through a different type of energy from electric energy.' ('Even though it is A, it can also become C or D' type). The example for the above is as Figure 1.

\begin{tabular}{|c|c|c|c|c|}
\hline $\begin{array}{c}\text { Existing } \\
\text { Characteristics } \\
\text { of Electric Fan }\end{array}$ & Type & & $\begin{array}{c}\text { Assumption } \\
\text { Reversal of } \\
\text { Existing } \\
\text { Characteristics } \\
\text { of Electric Fan }\end{array}$ & Type \\
\hline $\begin{array}{c}\text { An electric fan } \\
\text { has wings. }\end{array}$ & \multirow{3}{*}{$A$ is $B$} & $\rightarrow$ & $\begin{array}{l}\text { An electric fan } \\
\text { does not have } \\
\text { wings. }\end{array}$ & $\begin{array}{c}\mathrm{A} \text { is } \\
\text { not/does } \\
\text { not have } \mathrm{B}\end{array}$ \\
\hline $\begin{array}{l}\text { An electric fan } \\
\text { operates through } \\
\text { electric energy. }\end{array}$ & & $\rightarrow$ & $\begin{array}{l}\text { An electric fan } \\
\text { operates through } \\
\text { a different type } \\
\text { of energy from } \\
\text { electric energy. }\end{array}$ & $\begin{array}{l}\text { Even } \\
\text { though it is } \\
\text { A, it can }\end{array}$ \\
\hline $\begin{array}{l}\text { An electric fan is } \\
\text { not easy to } \\
\text { move because of } \\
\text { its large volume. }\end{array}$ & & $\rightarrow$ & $\begin{array}{l}\text { An electric fan is } \\
\text { easy to move } \\
\text { because of its } \\
\text { small volume. }\end{array}$ & $\begin{array}{c}\text { become C } \\
\text { or } \mathrm{D}\end{array}$ \\
\hline
\end{tabular}

Figure 1. Example of ideas discovered by students at the orientation through assumption reversal thinking skill

The students were instructed to discover ideas to produce new chemical cell based on the assumption reversal thinking skill by dividing into groups (6 groups with 3 5 people) after the orientation, and performed the activity during the general chemical experiment course. Groups in the general chemical experiment course were composed by students at the beginning of the semester. Thus, the interpretation of the research results show its limitations since the idea discovery activity may differ depending on the individual characteristics of students composing each group [14].

\subsection{Data Collection and Analysis}

The conversations and activities of the students were recorded and an observation journal was recorded during the period in which activities were conducted in order to examine the characteristics of discovering ideas by using the assumption reversal thinking skill. In addition, the students were instructed to individually record their own activities and thoughts in a report as specifically as possible. After completing all activities, the recorded materials, observation journal, and reports by students were comprehensively analyzed, and a post interview scenario was composed based on the analysis. The post interview scenario was composed of questions on the strengths of the assumption reversal thinking skill, difficulties in performing related activities, and reasons for the difficulties. And based on these questions, a semistructured post interview was conducted. All responses of the students regarding the post interview questions were recorded.

The reports by students and post interview contents were utilized as the main analysis materials through discussion between researchers. First of all, the elements and characteristics commonly appearing in the students' activity process were analyzed by three analyzers. After preparing preliminary categories based on the result obtained by the initial analysis, the process for seeking agreement among analyzers was repeated. In case there were uncertainties in the analysis, the result was determined by comprehensively utilizing the recorded materials and observation journal in order to enhance the validity of interpretation. When the agreement among analyzers reached $95 \%$ or more, one analyzer took charge of all analysis. In addition, the result and its meaning were only extracted after commonly consenting by the researchers in order to enhance reliability of the result analysis. The analysis of post interview materials was conducted in the same method and process as the analysis of student reports. Thus, after transcribing the recorded post interview materials, the interpretation process was repeated centering on the contents revealing the strengths of the assumption reversal thinking skill, characteristics of the related activities, and difficulties in the activities.

\section{Findings}

\subsection{Elements and Characteristics Appearing in the Idea Discovery Process Based on the Assumption Reversal Thinking Skill}

Table 1. Elements appeared in the idea discovery process based on the assumption reversal thinking skill

\begin{tabular}{|c|c|}
\hline Phase & Elements \\
\hline Idea generation & $\begin{array}{c}\text { Search for assumption reversal object } \\
\text { Extraction of internal or external attributes of } \\
\text { assumption reversal object } \\
\\
\text { Idea generation through assumption reversal } \\
\text { thinking skill }\end{array}$ \\
\hline Idea evaluation & $\begin{array}{c}\text { Evaluation standard setting } \\
\text { Evaluation } \\
\end{array}$ \\
\hline
\end{tabular}

The idea discovery process applying the assumption reversal thinking skill by undergraduate students in Korea could be classified into two phases of the 'idea generation' and the 'idea evaluation'. Moreover, in the idea generation phase, the elements of 'search for assumption reversal 
object', 'extraction of internal or external attributes of assumption reversal object', and 'idea generation through assumption reversal thinking skill' could be confirmed. And in the evaluation phase, the elements of 'evaluation standard setting', 'evaluation', and 'prototype' could be confirmed (Table 1). The details are as follows.

\subsubsection{Elements and Characteristics Appearing in the Idea Generation Phase}

The students searched the relevant information and knowledge to enhance the understanding level over chemical cells, which were the objects of assumption reversal. For example, the students examined how chemical cells were composed and understood the fundamental principle of chemical energy generation through the Voltaic cell and Daniel cell experiments. In addition, the students established an objective to resolve problem after comparing the strengths and weaknesses of the Voltaic cell and Daniel cell based on the obtained information or knowledge. The examples of such are as follows (Examples 1 and 2).

(Example 1)

Regarding the Daniel cell, the zinc sheet is immersed in a zinc sulfate aqueous solution, and the copper sheet is immersed in a copper sulfate aqueous solution. The two electrolyte solutions are connected through a salt bridge, and the reason of connecting with a salt bridge is to prevent the polarizing phenomenon from occurring.

Report by Student S10 (Group 3)

(Example 2)

Regarding the voltaic cell, because the reduction may occur at the same time as oxidation at the zinc plate, the electron does not entirely move to the copper sheet. However, because the reduction may not occur in the beaker where oxidation occurs in the Daniel cell, all reduction reactions occur in the cooper cup, which allows to have a relatively stable voltage. That is why it would be better to change the Daniel cell into a new cell.

\section{Report by Student S17 (Group 5)}

On the other hand, there were groups that immediately engaged in idea generation through assumption reversal thinking skill without inquiring into chemical cells. However, these groups acknowledged the limitations arising when engaging in idea generation without inquiring into chemical cells, and appeared to have conducted activities of examining the principle or basic structure of chemical cells. Thus, students having a low understanding level on chemical cells appeared to have experienced difficulties to reverse or change upon assumption reversal (Examples 3 and 4).

(Example 3)

I kept considering what fact to reverse upon thinking, however, I could not think of a way and felt pressure. Do I lack creativity..? (ellipsis) So I studied the Daniel cell again and then engaged in assumption reversal, and it became easier to know which parts to engage in assumption reversal.

Post Interview of Student S14 (Group 4)

\section{(Example 4)}

We have to change after selecting one fact. However, we did not know what to change in the cell. (ellipsis) I thought I knew chemical cells well because I learned of it before, however, I did not know which facts of chemical cells to use to engage in assumption reversal, which made me think that I should properly learn chemical cells again. (ellipsis)

Post Interview of Student S22 (Group 6)

As such, searching on the assumption reversal object was first conducted in the idea generation phase, which is probably because the clearly acknowledging the attributes or characteristics of the assumption reversal object was necessary due to the features of the assumption reversal thinking skill, which generates ideas by reversing the characteristics of a given object or matter. Students that finished inquiries on chemical cells extracted the internal or external attributes of chemical cells such as the electrolyte, electrode, and salt bridge. And then, they reversed or substituted the attributes with a new form. The example for such is as Table 2.

Table 2. The examples of ideas generated by assumption reversals thinking skill

\begin{tabular}{|c|c|c|}
\hline $\begin{array}{l}\text { Components of } \\
\text { Chemical Cell }\end{array}$ & $\begin{array}{c}\text { Internal or External } \\
\text { Attributes }\end{array}$ & $\begin{array}{l}\text { Ideas Extracted through } \\
\text { Assumption Reversal }\end{array}$ \\
\hline \multirow{4}{*}{ Electrolyte } & $\begin{array}{c}\text { Liquid electrolytes are } \\
\text { used. }\end{array}$ & $\begin{array}{c}\text { Liquid electrolytes are not } \\
\text { used. } \\
\text { Solid electrolytes are } \\
\text { used. }\end{array}$ \\
\hline & $\begin{array}{l}\text { Liquid electrolytes are } \\
\text { contained in a beaker. }\end{array}$ & $\begin{array}{l}\text { Solid electrolytes are } \\
\text { contained in a beaker. }\end{array}$ \\
\hline & $\begin{array}{l}\text { A large quantity of } \\
\text { liquid electrolyte is } \\
\text { necessary to contain the } \\
\text { electrodes. }\end{array}$ & $\begin{array}{l}\text { The quantity of liquid } \\
\text { electrolyte is set as a } \\
\text { minimum. } \\
\text { Liquid is not used as an } \\
\text { electrolyte. }\end{array}$ \\
\hline & $\begin{array}{l}\text { A solution containing } \\
\text { metallic ions are used } \\
\text { as the electrolyte. }\end{array}$ & $\begin{array}{c}\text { The solution that is } \\
\text { reduced is changed to a } \\
\text { solution including non- } \\
\text { metallic ion. }\end{array}$ \\
\hline \multirow{3}{*}{ Electrode } & $\begin{array}{c}\text { Metal electrodes are } \\
\text { used. }\end{array}$ & $\begin{array}{c}\text { Non-metal electrodes are } \\
\text { used. }\end{array}$ \\
\hline & $\begin{array}{l}\text { Different types of metal } \\
\text { electrodes are used } \\
\text { from each other. }\end{array}$ & $\begin{array}{c}\text { Same metal electrodes are } \\
\text { used. }\end{array}$ \\
\hline & $\begin{array}{l}\text { The electrodes are } \\
\text { fixed. }\end{array}$ & $\begin{array}{l}\text { The electrodes are not } \\
\text { fixed. }\end{array}$ \\
\hline \multirow[b]{2}{*}{ Salt Bridge } & $\begin{array}{l}\text { The two solutions are } \\
\text { connected with a salt } \\
\text { bridge. }\end{array}$ & A salt bridge is not used. \\
\hline & $\begin{array}{l}\text { The two solutions are } \\
\text { connected with the agar } \\
\text { salt bridge. }\end{array}$ & $\begin{array}{l}\text { The agar salt bridge is not } \\
\text { used, and the two } \\
\text { solutions are connected } \\
\text { with another material. }\end{array}$ \\
\hline \multirow{2}{*}{$\begin{array}{l}\text { Chemical } \\
\text { Reaction }\end{array}$} & $\begin{array}{l}\text { Spontaneous oxidation } \\
\text { and reduction occurs. }\end{array}$ & $\begin{array}{c}\text { ·Non-spontaneous } \\
\text { oxidation and reduction } \\
\text { occurs. }\end{array}$ \\
\hline & $\begin{array}{c}\text { The color of electrolyte } \\
\text { solution does not } \\
\text { change. }\end{array}$ & $\begin{array}{l}\text { The color of electrolyte } \\
\text { solution changes. }\end{array}$ \\
\hline
\end{tabular}

The students extracted new ideas by using assumption reversal on the existing attributes of chemical cells using liquid electrolytes as 'Liquid electrolytes are not used', and 'Solid electrolytes are used'. In addition, the students used assumption reversal on the existing attributes of chemical cells using a different type of metal electrode to extract ideas such as 'Non-metal electrodes are used' and 'Same metal electrodes are used'. There were groups creating ideas suggesting to avoid using salt bridges or substitute such with another substance or object based on the attributes of chemical cells that connect electrolytes with the salt bridge. In addition, an idea was generated from the chemical aspect of the Daniel cell, such as 'Nonspontaneous oxidation and reduction occurs' by reversing the attribute of 'Spontaneous oxidation and reduction occurs'. As such, the students generated ideas to produce new chemical cells based on the Daniel cell through the assumption reversal thinking skill. And the number of ideas per group were an average of seven. It appeared that the students were able to relatively easily perform this activity (Example 5). 
(Example 5)

I thought assumption reversal was to 'change in the exact opposite way.' For example, when applying assumption reversal to the characteristic of 'Chemical cells have A,' I thought the equation such as 'The new cell does not have A' would apply. I was able to easily form ideas through this method.

Report of Student S20 (Group 5)

As such, the elements of 'extraction of internal or external attributes of assumption reversal object' and 'idea generation through assumption reversal thinking skill' could be confirmed. It may be because the assumption reversal thinking skill, such as 'A is not/does not have B' or 'Even if it is A, it can also become C or D'. Therefore, the students could extract the internal or external attributes included in the assumption reversal object and reverse them.

On the other hand, there is a high likelihood of more useful ideas being suggested as the number of ideas increase [7]. Thus, thinking of an increased number of ideas is important in the initial process of generating ideas. The assumption reversal thinking skill can at least induce the generation of ideas per number of attributes included in the assumption reversal object. That is probably why students were able to create many ideas, and in particular, they were able to relatively easily perform the activity due to the assumption reversal thinking skill. Thus, it could be known that the assumption reversal thinking skill may apply as a useful thinking strategy to easily induce the generation of diverse ideas during the idea discovery process.

\subsubsection{Elements and Characteristics appearing in the Idea Evaluation Phase}

(Example 6)

We decided to make a cell using the same type of metal electrode, from the cell that normally uses the different type of metal electrode, while leaving the structure of the Daniel cell intact. (ellipsis)

(Experiment method)

1. Fix the concentration of solution as $0.5 \mathrm{M}$.

2. Cut $\mathrm{X}$ metal $(\mathrm{Fe}, \mathrm{Ni}, \mathrm{Pb})$ that is included in $\mathrm{Zn}>\mathrm{X}>\mathrm{Cu}$ in a constant size (control variable), and rub with sandpaper.

3. Put $\mathrm{ZnSO}_{4}$ solution at the anode and $\mathrm{CuSO}_{4}$ solution at the cathode, connect metal plates in the same type with an electrode, put a salt bridge between the solutions, and measure the voltage.

(Experiment result)

\begin{tabular}{|c|c|c|c|}
\hline $\begin{array}{c}\text { Oxidation } \\
\text { electrode } \\
\text { (zinc sulfate) }\end{array}$ & $\begin{array}{c}\text { Reduction } \\
\text { electrode } \\
\text { (copper sulfate) }\end{array}$ & $\begin{array}{c}\text { Voltage } \\
(\mathrm{V})\end{array}$ & $\begin{array}{c}\text { Current } \\
(\mathrm{mA})\end{array}$ \\
\hline $\mathrm{Zn}$ & $\mathrm{Cu}$ & 1.69 & 5.8 \\
\hline $\mathrm{Fe}$ & $\mathrm{Fe}$ & 0.78 & 3.3 \\
\hline $\mathrm{Ni}$ & $\mathrm{Ni}$ & 0.1 & - \\
\hline $\mathrm{Pb}$ & $\mathrm{Pb}$ & 0.76 & 3 \\
\hline
\end{tabular}

Report by Student S15 (Group 4)

It appeared that students that generated ideas based on the assumption reversal thinking skill performed evaluation on the ideas (Groups 1, 2, 4, and 5). To do such, the students set an evaluation standard and evaluated ideas pursuant to the standard. That's when they performed a simple experiment. For example, students in Group 4 set the evaluation standard as the operation status of a chemical cell. Subsequently, the students evaluated the suitability of the idea, which was 'The same metal electrode is used'. However, the opinions within the group did not concur regarding whether the chemical cell using the same type of metal electrode actually operate. Thus, in order to directly confirm the suitability of the idea, the students measured the voltage of the cell after cutting an iron plate in the same size and putting each plate in the zinc sulfate solution and copper sulfate solution. Afterwards, the students measured the voltage of the cell by experimenting with nickel and lead in the same method as iron. And then, they figured out the tendency and determined whether to discard this idea (Example 6).

In the process of evaluating the ideas, activities pertaining to prototype could be observed from most of the groups. A prototype is an early model made to test an idea's validity speedily [15]. Because prototype enables direct visualization of the idea and allows to obtain immediate feedback pursuant to the speedy attempts. Therefore, it may clarify the difference between one's intent and actual practice and provide experience on the likelihood of realization [15]. The prototype activities of the students were naturally conducted without separate instructions by the instructor in the idea evaluation phase. This may be because the process of evaluating the likelihood of idea realization was necessary by directly making a prototype due to the characteristics of the assumption reversal thinking skill leading new forms of ideas that do not conform to the existing theories or concepts.

On the other hand, the two groups (Groups 3 and 6) did not even try to evaluate the generated ideas. The students appeared to have thought that there was no value in trying to evaluate the ideas because the ideas generated by the assumption reversal thinking skill did not appropriate to existing theories. For example, Group 3 was able to generate various ideas through the assumption reversal thinking skill, however, appeared to have thought that the evaluation itself did not have meaning because the generated idea itself did not conform to the chemical cell theory (Example 7). Group 6 also generated ideas such as 'Salt bridge is not used', however, because not using a salt bridge in chemical cell is not explained by existing theories, the group appeared to have decided not to proceed with evaluation (Example 8).

(Example 7)

\begin{tabular}{ll} 
Student S9 & $\begin{array}{l}\text { There were many ideas generated through assumption } \\
\text { reversal thinking skill. However, the idea does not } \\
\text { conform to the theories, and how could we say it is correct } \\
\text { or not... }\end{array}$ \\
\hline Researcher & What did the other members think? \\
\hline Student S9 & $\begin{array}{l}\text { Other students also said it does not conform to the theory! } \\
\text { Or, 'It doesn't work!' That is why I gave up. }\end{array}$ \\
\hline
\end{tabular}

Post Interview of Student S9 (Group 3)

(Example 8)

(ellipsis) The two solutions in a chemical cell are connected through a salt bridge, and our group made a reverse assumption that a salt bridge is not used. However, we thought that not using a salt bridge itself does not conform to the chemical cell theory, thus, decided not to evaluate this part.

Report of Student S21 (Group 6)

The assumption reversal thinking skill leads the generation of ideas in a new form that does not conform to existing theories or concepts. Thus, when evaluating ideas having such characteristics in existing theoretical frames, the idea may be thought as 'wrong' or 'erroneous,' which may disturb the evaluation of the idea itself. Although the background knowledge is important in the idea discovery process, one may become to have a closed viewpoint of trying to resolve or understand a problem in the method experienced in the past when depending on knowledge 
[16]. As a result, for more effective evaluation over the idea in the creative problem solving adopting the assumption reversal thinking skill, a method to deter intervention of individual values or theoretical judgments on the formed idea itself would be necessary.

\subsection{Circulation of Elements appearing in the Idea Discovery Process based on Assumption Reversal Thinking Skill}

It could be known that the elements appearing in the idea discovery process were circulated by closely interacting with the other. Thus, the 'idea generation phase' and the 'idea evaluation phase' were repeatedly circulated. And in the idea evaluation phase, the 'evaluation standard setting', 'evaluation', 'prototype' elements were also circulated repeatedly. The details are as follows.

\subsubsection{Circulation between Idea Generation Phase and Idea Evaluation Phase}

The repeating elements and the order of their appearance differed per group. However, it could be known that overall, the idea generation phase and the idea evaluation phase were being repeatedly circulated (Figure 2).

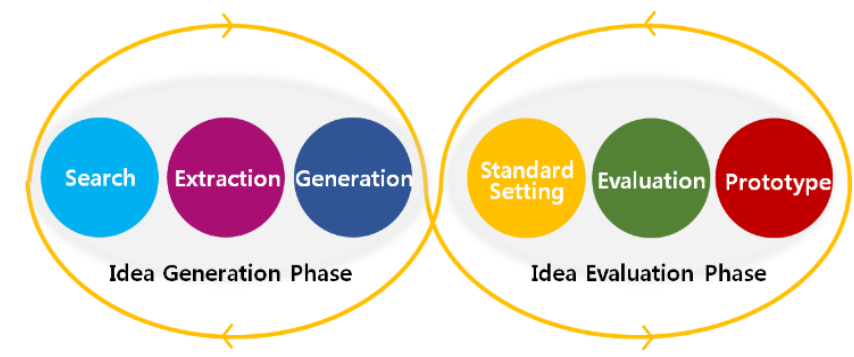

Figure 2. Circulation of idea generation phase and idea evaluation phase

(Example 9)

- We examined the external structure of the Daniel cell. We captured the characteristic that there is aqueous solution inside the salt bridge and the beaker containing the electrodes. We tried to make a cell that does not use any aqueous solution at all by applying assumption reversal to this characteristic.

$(\rightarrow$ Idea generation $)$

- However, after examining the 'cell section' of a textbook in order to examine the principle on whether this idea is available in theory, we found that there were no cells that did not use any aqueous solution. As a result of searching for information, we determined that it is impossible to make a cell that does not use any aqueous solution, and decided to abandon this idea.

$(\rightarrow$ Idea evaluation and disposal)

- We engaged in assumption reversal again. The solutions of chemical cells are connected with solutions, so we tried to make a chemical cell that does not use a salt bridge.

$(\rightarrow$ Idea generation)

\section{$\downarrow$}

- We pondered on how to connect the two beakers instead of using the salt bridge. Because the salt bridge not only plays the role of matching balance of electric charge, but also plays the role of connecting two electrolytes, we thought that an electric wire would play the role of the salt bridge instead.

$(\rightarrow$ Idea evaluation and selection)

Report of Student S4 (Group 1)

For example, Groups 1 and 4 generated one idea based on the assumption reversal thinking skill and conducted idea evaluation. In case the idea did not satisfy the evaluation standard or a method to implement the idea could not be found, the students immediately disposed of the idea. Subsequently, the students re-generated a new idea by entering the idea generation phase again. Then, the students re-engaged in evaluation on the generated idea. Groups 1 and 4 appeared to have continuously repeated this process until one idea was selected (Example 9). Unlike Groups 1 and 4, Groups 2 and 5 appeared to have produced all possible ideas through assumption reversal thinking skill and evaluated the suitability of the ideas in order. Thus, the students conducted evaluation on one idea among the generated ideas and disposed of the idea when the idea did not satisfy the evaluation standard. And then, they appeared to have re-engaged in evaluation on one idea among the ideas already generated.

Generally, in order to discover ideas that are creative and have high likelihood of realization, there is a need for divergent thinking, which is to search for an alternative based on related knowledge, and convergent thinking, which is to select and evaluate the alternative, to repetitively occur through dynamic interaction [15,17]. Thus, there is a need to compose activities that may assist the revelation of divergent thinking and convergent thinking during the idea discovery process in a circulative form, rather than a consecutive form. In the creative problem solving programs provided to Korean students, related strategies were intentionally included so that the two thinking may be repeatedly formed in circulation or instruction by an instructor was demanded together. However, when applying the assumption reversal thinking skill to students, the repetitive circulation could be naturally formed between the idea generation phase and the idea evaluation phase even without a particular strategy or prior instruction by the instructor. The characteristics of assumption reversal thinking skill that can be easily and speedily utilized by students was mentioned as the reason. Thus, it was explained that the idea generation and the idea evaluation could be repetitively performed because the students were able to relatively easily generate new ideas through the assumption reversal thinking skill even when the generated idea did not pass the evaluation standard (Example 10).

(Example 10)

\begin{tabular}{ll}
\hline & $\begin{array}{l}\text { As mentioned earlier, it is easy to engage in assumption } \\
\text { reversal. We just need to change certain things. Because }\end{array}$ \\
Student S2 & $\begin{array}{l}\text { we could generate ideas, we quickly experimented on } \\
\text { whether an idea was available, and did not worry too } \\
\text { much even if the idea did not work. Because we could } \\
\text { generate more ideas. }\end{array}$ \\
\hline Researcher & What about other students? \\
\hline Student S3 & $\begin{array}{l}\text { Even if the idea did not work, we could quickly generate } \\
\text { other ideas, thus, repeating the process did not feel as a } \\
\text { pressure as much compared to other problem-solving } \\
\text { programs. }\end{array}$ \\
\hline Student S4 & $\begin{array}{l}\text { Assumption reversal lowers the burden on generating } \\
\text { many ideas, and because we have many ideas, we can } \\
\text { select the best idea after quickly evaluating whether the } \\
\text { idea is available... (ellipsis) }\end{array}$ \\
\hline
\end{tabular}
Post Interview of Group 1

It could be known that the assumption reversal thinking skill was utilized as a thinking frame lowering the cognitive burden of the students during idea generation. Thus, even if the idea was not able to pass the evaluation phase, the students could easily generate other ideas 
without burden, and as a result, the idea generation phase and the idea evaluation phases could be naturally circulated several times. As a result, it could be known that the assumption reversal thinking skill is an effective thinking skill leading circulative feedback between divergent thinking and convergent thinking, while lowering the cognitive burden of students regarding idea generation.

\subsubsection{Circulation among Evaluation-related Elements in the Idea Evaluation Phase}

It could be observed from most of the groups that the 'evaluation standard setting' and 'evaluation' elements circulated repetitively by closely interacting with the 'prototype' element in the evaluation phase. For example, Groups 2 and 4 directly evaluated the validity of the idea through prototype. Thus, the groups showed the circulation of the 'evaluation standard setting', 'suitability evaluation of idea through prototype', 'idea disposal and generation', or 'final idea selection'. That's when the groups have also re-searched the references related to chemical cell. Such circulation was repeatedly conducted until selecting one final idea (Figure 3).

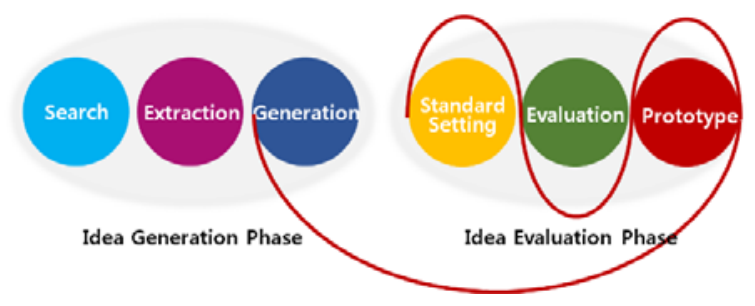

Figure 3. Circulation among evaluation-related elements by groups 2 and 4

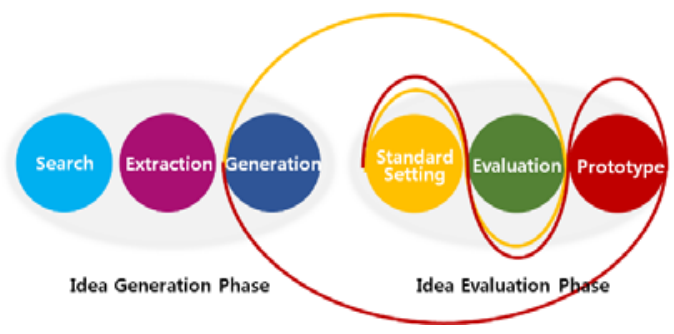

Figure 4. Circulation among evaluation-related elements by groups 1 and 5

Groups 1 and 5 performed the idea evaluation in two stages. In the first stage, the 'evaluation standard setting', 'idea evaluation pursuant to the evaluation standard', 'idea disposal', and 'idea generation' were circulated. In the second stage, the 'prototype of idea passing the evaluation standard', 'idea evaluation through prototype', 'idea disposal and generation', or 'final idea selection' were circulated. Thus, the students first evaluated the suitability of the idea pursuant to the evaluation standard. They disposed the idea determined as not suitable to the evaluation standard, and then generated another idea (the first stage). Afterwards, the students made a prototype of the idea passing the evaluation standard. Then, they reconfirmed the suitability of the idea. And they discarded the idea in case of failing to find a method to implement the idea or in case of discovering an unexpected problem. Afterwards, the students re-generated an idea, and appeared to have returned to the first stage of evaluating the idea (the second stage). As such, the circulation of the two stages was repeated until one final idea was selected. Moreover, it could be confirmed that the principles of chemical cell or related knowledge were continuously researched during the evaluation, just as Groups 2 and 4 (Figure 4, Example 11).

(Example 11)

- After completing idea generation, we established the likelihood of realization at the laboratory as the standard and thought of making a chemical cell with a solid electrolyte, since all electrolytes of chemical cells are liquid. However, it was not easy to think of a substance that is solid and electrolyte at the same time. Thus, we thought of using agar, however, we excluded the possibility because it takes a long time for agar to solidify.

First stage: (evaluation standard setting $\rightarrow$ idea evaluation pursuant to the evaluation standard $\rightarrow$ idea disposal)

\section{$\downarrow$}

- Thus, we evaluated an idea based on assumption reversal, to use the same metal electrode of the Daniel cell, instead of the different metal electrodes, and tried to use a metal with different oxidation state to make the cell to operate. Thus, a realization method of using a corroded iron and non-corroded iron was suggested, however, we discarded this idea because it was not easy to find a corroded iron.

First stage: (idea generation $\rightarrow$ idea evaluation pursuant to the evaluation standard $\rightarrow$ idea disposal)

$$
\downarrow
$$

- We decided to evaluate an idea of using a solid electrolyte instead of a liquid electrolyte again. We thought that we could make a solid electrolyte by applying liquid electrolyte into cotton.

First stage: (idea generation $\rightarrow$ idea evaluation pursuant to the evaluation standard $\rightarrow$ idea selection)

- We directly made a chemical cell to examine whether the electrolyte applied on the cotton actually operated. While searching materials, we thought that by using foil and charcoal, the charcoal would become the reduction electrode and aluminum foil would become the oxidation electrode. We then put the cotton dipped with salt water between the charcoal and aluminum foil. We confirmed that the chemical cell worked. That is why we finally selected this idea.

Second stage: (prototype of idea passing the evaluation standard $\rightarrow$ idea evaluation through prototype $\rightarrow$ final idea selection)

Report of Student S16 (Group 5)

As such, the evaluation-related elements repetitively circulated by interacting with each other in the idea evaluation phase, and this circulation may improve the quality of ideas. However, it could be confirmed that such circulation naturally appeared in the idea discovery process applying the assumption reversal thinking skill. In particular, the prototype was accompanied in the evaluation phase. It has been reported that when prototype is conducted together during evaluation the value of a generated idea, the result has significant effect on successful problem solving [15]. However, there have been almost no research results reporting that prototype have been naturally performed by students without mentioning or instructions by an instructor in a creative problem solving program attempted in Korea until now. However, the prototype activity of students could be observed in the idea discovery process applying the assumption reversal thinking skill. This can be because the confirming the possibility of idea was necessary due to the characteristics of idea by assumption reversal that is hard to explain through existing common sense. The students actually responded in the post interview that they could not clearly determine whether an idea was actually realizable because the generated idea was a reversed assumption of the original form, and they needed to conduct a simple experiment to confirm the matter (Example 12).

Thus, it could be known that the assumption reversal is an effective thinking skill that can assist in achieving idea 
discovery by repetitively inducing critical evaluation based on a prototype on diverse ideas.

(Example 12)

Because the ideas based on assumption reversal may not conform to the theory and not be correct when actually

Student S6 conducting the experiment, to more accurately select an idea, I thought that a process of confirming whether the experiment works or not would be necessary.

Yes, I could confirm whether it actually worked by simply personally making it. That is why I thought that a process

Student S8 of making a prototype was necessary, and could more certainly determine whether this cell would operate by directly making the prototype.

Post Interview of Group 2

\section{Conclusions and Implications}

Korean students showed the activity in the idea discovery process as more difficult than activities in other processes of the creative problem solving. So, there is a need to provide the methodological aspect in more detail in order to help their idea generation, and the assumption reversal thinking skill should be considered as one alternative. This research examined the elements and the characteristics appearing in the idea discovery process based on the assumption reversal thinking skill by Korea's undergraduate students. This research also examined the possibility of the assumption reversal thinking skill as an alternative to assist the idea discovery process.

As a result of the research, the idea discovery process applying the assumption reversal thinking skill could be categorized into the idea generation phase and the idea evaluation phase. In addition, in the idea generation phase, the elements of 'search for assumption reversal object', 'extraction of internal or external attributes of assumption reversal object', and 'idea generation through assumption reversal thinking skill' could be confirmed. In the idea evaluation phase, the elements of 'evaluation standard setting', 'evaluation', and 'prototype' could be confirmed. Thus, the students examined the principles or component elements of chemical cell, the object of assumption reversal. And then, they extracted internal or external attributes of the chemical cell. By reversing or eliminating the extracted internal or external attributes, various ideas were easily generated. Afterwards, the evaluating the generated ideas was conducted. To do this, the students set the evaluation standard and conducted evaluation pursuant to the evaluation standard. It appeared that ideas with high problem solving capability were selected through prototype.

The circulation of elements appearing in the idea discovery process could be confirmed as well. For example, the idea generation phase and the idea evaluation phase were repeatedly circulated by close interaction with each other. Moreover, evaluation-related elements in the idea evaluation phase were repeatedly circulated by close interaction. But there were differences shown per group.

For example, two groups showed the circulation of the 'evaluation standard setting', 'suitability evaluation of idea through prototype', 'idea disposal and generation', or 'final idea selection'. Thus, there was direct idea evaluation through a prototype. In two other groups, the circulation was conducted in two stages. In the first stage, the 'evaluation standard setting', 'idea evaluation pursuant to the evaluation standard', 'idea disposal', and 'idea generation' were circulated. In the second stage, the 'prototype of idea passing the evaluation standard', 'idea evaluation through prototype', 'idea disposal and generation', or 'final idea selection' were circulated. Thus, the prototype was circulated only for idea passing the evaluation standard. Based on such result, the characteristics and possibilities of the assumption reversal thinking skill may be proposed as follows.

First, there is a likelihood that the assumption reversal thinking skill will reduce cognitive pressure of students regarding idea generation and assist in generating diverse and creative ideas. Thus, the assumption reversal thinking skill, such as 'A is not/does not have B' or 'Even if it is A, it can also become $C$ or D', may apply as an effective thinking frame to assist the generation of diverse and unique ideas.

Second, there is a likelihood that the assumption reversal thinking skill may assist students in selecting ideas with high problem solving capability by repetitively inducing evaluation activities based on prototype. It is being reported that Korean students lack the ability to critically examine their own thoughts or ideas through an adequate criteria after generating an idea [18]. However, the assumption reversal thinking skill repetitively and naturally induced the evaluation activities allowing to critically examine the ideas. The assumption reversal thinking skill can accordingly be utilized as a skill to provide opportunities to evaluate the limitations of an idea by naturally inducing prototype. On the other hand, most of the ideas generated through the assumption reversal thinking skill exhibit the characteristics that it is difficult to explain with existing theories or concepts. Thus, there is a possibility that the generated idea itself may induce the students' resistance, which would disturb the evaluation process of the idea. Therefore, preparation of strategy to exclude bias may be needed.

Third, the assumption reversal thinking skill appeared to have a likelihood of being utilized as a cognitive skill to assist discovery of ideas while repetitively forming harmony between divergent thinking and convergent thinking. Due to the characteristics of the assumption reversal thinking skill that decreases the cognitive burden on idea generation, students may naturally engage in idea generation activity again even when failing to select an idea through evaluation. Moreover, the students could repetitively experience divergent thinking and convergent thinking through such process. Therefore, the assumption reversal thinking skill may be used as a cognitive skill stimulating discovery of ideas based on the divergent and convergent thinking.

This research result may provide basic information to seek an application method of the assumption reversal thinking skill suitable to elementary and secondary school students in Korea. However, there are limits in understanding in-depth the strengths and weaknesses of the idea discovery process based on the assumption reversal thinking skill, only with the reports and post interviews by the undergraduate students. Accordingly, there is a need to conduct subsequent quantitative and qualitative research over elementary and secondary school students for preparing strategies and gaining an in-depth understanding on the assumption reversal thinking skill based on the results of this research. In particular, the 
activity in the idea discovery process may differ depending on the characteristics of individual students composing a group. Therefore, a research to prepare strategies based on the assumption reversal thinking skill considering the characteristics of groups should be conducted alongside as well.

\section{References}

[1] Kang, S.J., Kim, H.J., and Lee, K.J, The creative inquiry activity program for science-gifted students (I), Bookshill Publishers, Seoul, 2011.

[2] Choi, B.Y., and Kang, B.N, "Problem-based learning to enhance creativity”, Korean Society for Creativity Education, 10 (2), 27-44, 2010.

[3] Treffinger, D.J., Isaksen, S.G., and Dorval, K.B, Creative problem solving: An introduction (3rd Ed.), Prufrock Publishers, Waco, TX, 2000.

[4] Kim, J.S, "Elementary school students' creative problem solving process and the change by teacher's guidance", Journal of Korean Practical Arts Education, 16 (1), 1-22, 2010.

[5] Lee, K.H., Choi, Y., and Hwang, S, "Development of creative problem solving program based on team project”, Korean Society for Creativity Education, 11 (2), 141-160, 2011.

[6] Lee, J.Y., Koo, Y.M., Nam, M., Park, S., Kim, B., Park, D., Seo, J., Go, B., and Jin, S.U, "Analysis of effects of learner factors on creative problem solving programs in elementary school social studies”, The Journal of Educational Information and Media, 13 (1), 279-308, 2007.

[7] Osborn, A.F, Applied imagination: Principles and procedures of creative thinking, Charles Scribner's Sons Publishers, New York, 1953.

[8] Choi, B., and Park, M, "Effects of creativity education program through the creative problem solving model”, The Korea Journal of Education Methodology Studies, 16 (2), 1-28, 2004.
[9] Yeo, J.S, Contrarian marketing, One \& Books Publishers, Seoul, 2011.

[10] Kang, S.J., Park, J.Y., and Yoon, J, "The investigation on the possibilities of assumption reversal thinking skill: Focus on the characteristics of the idea generation process by university Students”, Journal of the Korean Association for Research in Science Education, 33 (2), 501-510, 2013.

[11] Isaksen, S.G., and Deschryver, L, "Making a difference with CPS: A summary of the evidence”, In S. G. Isaksen (Ed.). Facilitative leadership: Making a difference with CPS, Kendall-Hunt Publishers, Dubuque, IA, 2000.

[12] Jeon, G.W, "Kindergarten teachers' perception on brainstorming", Kindergarten Teachers' Perception on Brainstorming, 2 (2), 1-23, 1997.

[13] Seong, T.J., and Si, G.J, The research methodology, Hakjisa Publishers, Seoul, 2011.

[14] Firestien, R.L, "Effects of creative problem solving training on communication behaviors in small groups", Small Group Research, 21 (4), 507-521, 1990

[15] Welch, M, "Students' use of three-dimensional modelling while designing and making a solution to a technological problem", International Journal of Technology and Design Education, 8 (3), 241-260, 1998.

[16] Frensch, P. A., and Sternberg, R.J, "Expertise and intelligent thinking: When is it worse to know better?" In R. J. Sternberg (Ed.), Advances in the psychology of human intelligence, Vol. 5, Lawrence Erlbaum Publishers, Hillsdale, NJ, 1989.

[17] Mioduser, D., and Kipperman, D, "Evaluation/Modification cycles in junior high students' technological problem solving”, International Journal of Technology and Design Education, 12 (2), 123-138, 2002.

[18] You, J.Y., Park, Y.O., and Noh, T.H, "The influences of inquiry learning-based analogical experiments on experimental design processes of science-gifted students", Journal of the Korean Association for Research in Science Education, 31 (6), 986-997, 2011. 